\title{
A study of $\mathrm{PM}_{2.5}$ and $\mathrm{PM}_{10}$ concentrations in the atmosphere of large cities in Gansu Province, China, in summer period
}

\author{
Mikalai FilonchyK ${ }^{1, *}$, Haowen Yan $^{2}$, Shuwen Yang $^{2}$ and Volha Hurynovich ${ }^{1}$ \\ ${ }^{1}$ School of Environmental and Municipal Engineering, Lanzhou Jiaotong University, Lanzhou 730070, China. \\ ${ }^{2}$ Department of GIS, Lanzhou Jiaotong University, Lanzhou 730070, China. \\ ${ }^{*}$ Corresponding author. e-mail: filonchyk.mikalai@gmail.com
}

Due to rapid economic growth of the country in the last 25 years, particulate matter (PM) has become a topic of great interest in China. The rapid development of industry has led to an increase in the haze created by pollution, as well as by high levels of urbanization. In 2012, the Chinese National Ambient Air Quality Standard (NAAQS) imposed 'more strict' regulation on the PM concentrations, i.e., 35 and $70 \mu \mathrm{g} / \mathrm{m}^{3}$ for annual $\mathrm{PM}_{2.5}$ and $\mathrm{PM}_{10}$ in average, respectively (Grade-II, GB3095-2012). The Pearson's correlation coefficient was used to determine the linear relationship of pollution between pollution levels and weather conditions as well as the temporal and spatial variability among neighbouring cities. The goal of this paper was to investigate hourly mass concentration of $\mathrm{PM}_{2.5}$ and $\mathrm{PM}_{10}$ from June 1 to August 31, 2015 collected in the 11 largest cities of Gansu Province. This study has shown that the overall average concentrations of $\mathrm{PM}_{2.5}$ and $\mathrm{PM}_{10}$ in the study area were 26 and $66 \mu \mathrm{g} / \mathrm{m}^{3}$. In $\mathrm{PM}_{2.5}$ episode days (when concentration was more than $75 \mu \mathrm{g} / \mathrm{m}^{3}$ for $24 \mathrm{hrs}$ ), the average concentrations of $\mathrm{PM}_{2.5}$ was 2-3 times higher as compared to non-episode days. There were no observed clear differences during the weekday/weekend PM and other air pollutants $\left(\mathrm{SO}_{2}, \mathrm{NO}_{2}, \mathrm{CO}\right.$ and $\left.\mathrm{O}_{3}\right)$ in all the investigated cities.

\section{Introduction}

In recent decades, rapidly expanding economic development has resulted in tremendous increase in energy consumption, air pollutant emission, and air pollution in China. This deterioration of air quality has been one of the main environmental problems for the country. Past studies of $\mathrm{PM}_{2.5}$ (particle's aerodynamic diameter less than $2.5 \mu \mathrm{m}$ ) showed that annual average concentrations had exceeded $90 \mu \mathrm{g} / \mathrm{m}^{3}$ in Guangzhou (Hagler et al. 2006), over $120 \mu \mathrm{g} / \mathrm{m}^{3}$ in Beijing (Yao et al. 2002; Guinot et al. 2007) and $95 \mu \mathrm{g} / \mathrm{m}^{3}$ in Shanghai (Feng et al. 2009). A study of air pollution in Lanzhou showed that the average concentration of $\mathrm{PM}_{2.5}$ in 2007-2009 was $90 \mu \mathrm{g} / \mathrm{m}^{3}$ (Fang et al. 2014), and that of $\mathrm{PM}_{10}$ in the same period exceeded 129, 132 and $150 \mu \mathrm{g} / \mathrm{m}^{3}$, respectively (Hou et al. 2011) and made $150 \mu \mathrm{g} / \mathrm{m}^{3}$ (Tao et al. 2014). Recent studies of Zhai et al. (2015) showed that the average monthly concentration of $\mathrm{PM}_{2.5}$ and $\mathrm{PM}_{10}$ in winter months of 2013 had exceeded 95 and $290 \mu \mathrm{g} / \mathrm{m}^{3}$, and in summer months, 48 and $110 \mu \mathrm{g} / \mathrm{m}^{3}$, respectively, which greatly exceeded the World Health Organization (WHO) annual average guideline value of $10 \mu \mathrm{g} / \mathrm{m}^{3}$ (WHO 2005).

Atmospheric particulate matters (PM), i.e., $\mathrm{PM}_{10}$ and $\mathrm{PM}_{2.5}$ (particles of aerodynamic diameter $\leq 2.5 \mu \mathrm{m}$ ), attracted more and more attention in recent years due to its important roles in atmospheric

Keywords. China; Gansu Province; particulate matter; episode days; correlations; air pollution. 
processes, adverse effects on health, and global climate. Ambient air quality is primarily affected by particulate matter (PM), carbon monoxide $(\mathrm{CO})$, sulfur dioxide $\left(\mathrm{SO}_{2}\right)$, nitrogen dioxide $\left(\mathrm{NO}_{2}\right)$ and ozone $\left(\mathrm{O}_{3}\right)$ concentrations in the atmosphere.

Impact of air pollution is particularly important in many developing countries where the problem of air pollution is becoming increasingly serious (Gupta et al. 2003). In China, a considerable number of studies have been dedicated to investigate the variations of concentrations of PM and gaseous pollutants during meteorological phenomena, e.g., dust storms and haze episodes (Xie et al. 2005; Choi et al. 2008; Chu et al. 2008a, b; Yang et al. 2011; Fan et al. 2013). Other studies have considered pollutant conditions in one large city, several cities, or a region (An et al. 2007; Chu et al. 2008a; Quan et al. 2008; Wang et al. 2009; Li et al. 2010; Fan et al. 2014). Other investigators focused on the chemical components of $\mathrm{PM}_{2.5}$ in several large cities ( $\mathrm{Yu}$ and Yu 2012; Zhang et al. 2012).

This paper presents the results of a detailed hourly, daily and seasonal study of the composition, concentration, and sources of air pollution measured in 11 cities of Gansu Province during the summer period of 2015. The spatial and temporal variations of these pollutants were compared. There are several reasons that pushed us to perform this study. First: high concentration of PM pollution has been reported in summer period in this region. Second: the problem of air pollution has caused considerable public awareness in China. Therefore, investigations into the spatio-temporal variation of concentrations of PM and gaseous pollutants across China are necessary and important. Third: previous studies in the region mainly covered small territory (e.g., Ta et al. 2004). The main objective of this work is to present updated information about the size and characteristics of the summer $\mathrm{PM}_{2.5}$ and $\mathrm{PM}_{10}$, as well as main gas pollutants of ground measurement data in 11 cities of Gansu Province. This knowledge can further be used to investigate the sources and PM management strategies.

\section{Methods}

\subsection{Investigated area}

Gansu Province has a population of 25.8 million (as of 2010) and covers an area of $454,000 \mathrm{~km}^{2}$; the average altitude is $1000-3000 \mathrm{~m}$ above sea level. The province is located in the northwest of China, between the Tibetan highland and the Mongolian Plateau; it borders the Inner Mongolia Autonomous Region and Ningxia Hui in the northeast, Shaanxi in the east, Sichuan in the south, Qinghai in the southwest, Xinjiang in the west, and a small section of the Mongolian border in the north (Govi-Altai Province). The center of province and the largest city is Lanzhou.

The province contains highly developed oil production and refining, extraction of coal, copper, and iron ore as well as non-ferrous metallurgy, machinebuilding, chemical, petrochemical, metal processing, textile industry, the production of fissile materials, building materials, and electronics. The area suffers from dust storms from the Gobi desert, especially in winter. The main source of air pollution includes industrial emissions, as well as coal-fired power stations (Wang et al. 2008).

Eleven cities in the Gansu Province, i.e., Lanzhou, Jiayuguan, Zhangye, Wuwei, Baiyin, Dinxi, Tianshui, Qingyang, Pingliang, Jinchang, Longnan, are covered on this study (figure 1).

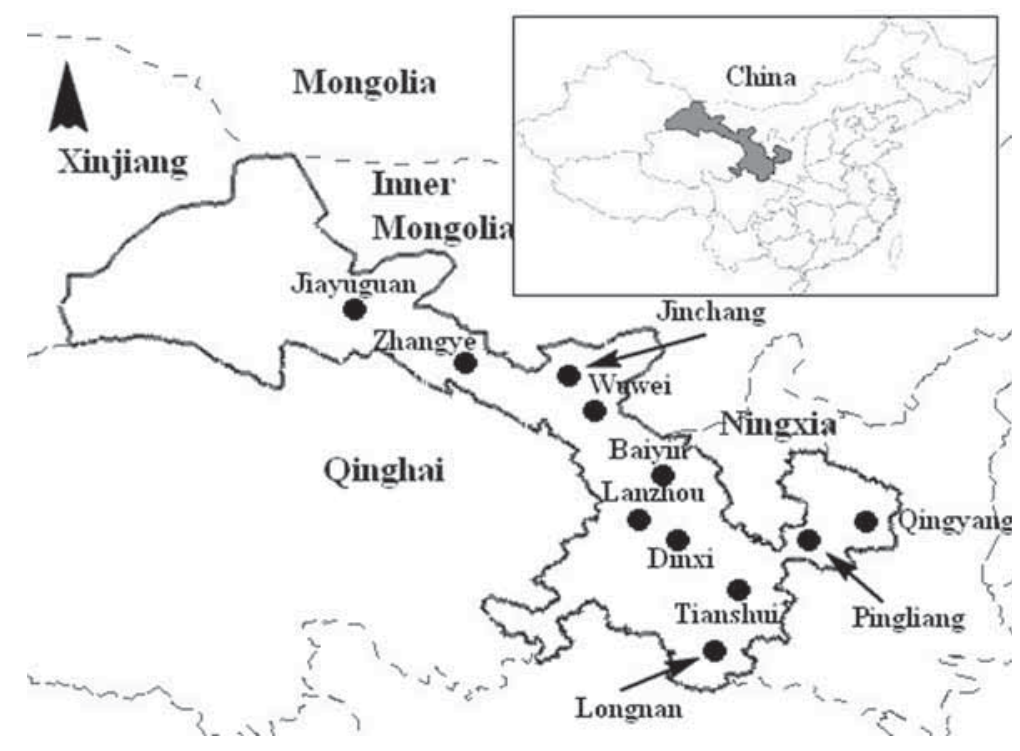

Figure 1. Geolocation of the study area in Gansu Province, northwestern China. 


\subsection{Data source}

The mass concentrations of $\mathrm{PM}_{2.5}, \mathrm{PM}_{10}, \mathrm{SO}_{2}, \mathrm{NO}_{2}$, $\mathrm{CO}$ and $\mathrm{O}_{3}$ were recorded by the Data Centre, the Ministry of Environmental Protection of the People's Republic of China (http://datacenter.mep. gov.cn/ and 113.108.142.147:20035/emcpublish/). Data presented in this study were obtained from the national air quality monitoring stations located in each city studied in the period from June 1, 2015 to August 31, 2015. Automated monitoring systems have been constructed for measuring the ambient concentration of $\mathrm{SO}_{2}, \mathrm{NO}_{2}, \mathrm{O}_{3}$ and $\mathrm{CO}$ in accordance with the norm from the China Environmental Protection Standards HJ193-2013 (MEP 2013a), as well as $\mathrm{PM}_{2.5}$ and $\mathrm{PM}_{10}$ according to the China Environmental Protection Standards HJ655-2013 (MEP 2013b). Ground-based meteorological parameters, surface wind speed (WS), temperature $(\mathrm{T})$, and relative humidity $(\mathrm{RH})$ at the surface of the ground, and the meteorological observations were received from the National Meteorological Center of CMA (http:/nmc.cn/).

\section{$2.3 P_{2.5 / 10}$ concentration data and statistical analysis}

In order to protect air quality as well as monitoring air quality standards, the Ministry of Environmental Protection of the People's Republic of China (MEP) and Gansu Provincial Department of Environmental Protection, constructed more than 28 air quality monitoring stations in the cities of Gansu. These ground-based monitoring stations measure the concentration of weighted particles in the air, show hourly and daily average concentrations. In this work we used a daily average $\mathrm{PM}_{2.5}$ mass concentration (in $\mu \mathrm{g} / \mathrm{m}^{3}$ ). The $\mathrm{PM}_{2.5 / 10}$ mass concentrations from these stations were measured using a Tapered Element Oscillating Microbalance (TEOM 1400a) with a precision of $\pm 1.5 \mu \mathrm{g} / \mathrm{m}^{3}$ for the hourly mean value, and of $\pm 0.5 \mu \mathrm{g} / \mathrm{m}^{3}$ for the daily 24-hour average value, and calculates realtime PM mass concentrations. With TEOM 1400a, sampling and determining the mass of the particles is performed at specific time intervals, with following weighting and measurement of their deposition on the filter. The filter is attached to the vibrating hollow conical glass tube whose frequency is influenced by the load of the filter. TEOM's opening is heated to $50^{\circ} \mathrm{C}$ in order to eliminate the effect of the condensation and evaporation of water particles in the filter. This heating aerosol flow is caused by the loss of semi-volatile species (Charron et al. 2004; Charron and Harrison 2005). The data from all stations were utilized in this research. Detailed information on the monitoring sites is given in table 1.

Average hourly and per diem concentrations of pollutants for each of the cities, as well as data were obtained by averaging the hourly data from all air quality monitoring station. Daily average concentrations of all pollutants were computed after 16 hours of data receiving.

The days when the daily mean concentrations were higher than the Grade II standard $\left(\mathrm{PM}_{2.5} \geq\right.$ $75 \mu \mathrm{g} / \mathrm{m}^{3}$ and $\mathrm{PM}_{10} \geq 150 \mu \mathrm{g} / \mathrm{m}^{3}$ ) are defined as PM episode days and days with average concentration of less than quality I standard $\left(\mathrm{PM}_{2.5} \leq\right.$ $35 \mu \mathrm{g} / \mathrm{m}^{3}$ and $\mathrm{PM}_{10} \leq 50 \mu \mathrm{g} / \mathrm{m}^{3}$ ) are determined as non-episode days. Pearson's correlation coefficient was utilized to define the linear relationship between the factors affecting the level of pollution and contamination. Multivariate analysis was conducted to assess the main factors related to $\mathrm{PM}_{2.5 / 10}$ levels under background conditions and potentially unfavourable factors (Hatch et al. 1982; Breiman and Friedman 1985).

Table 1. Basic Information of the 11 studied cities.

\begin{tabular}{|c|c|c|c|c|}
\hline City & $\begin{array}{c}\text { Number of } \\
\text { monitoring sites }\end{array}$ & $\begin{array}{l}\text { Population } \\
(\text { as of } 2010)^{*}\end{array}$ & $\begin{array}{l}\text { Area of the } \\
\text { city }\left(\mathrm{km}^{2}\right)\end{array}$ & $\begin{array}{l}\text { Latitude and } \\
\text { longitude }\end{array}$ \\
\hline Jiayuguan & 2 & 231,853 & 2935 & $\mathrm{~N} 39^{\circ} 49^{\prime} \mathrm{E} 98^{\circ} 18^{\prime}$ \\
\hline Zhangye & 2 & $1,199,515$ & 40,874 & $\mathrm{~N} 38^{\circ} 36^{\prime} \mathrm{E} 100^{\circ} 27^{\prime}$ \\
\hline Jinchang & 3 & 464,050 & 8896 & $\mathrm{~N} 38^{\circ} 29^{\prime} \mathrm{E} 102^{\circ} 10^{\prime}$ \\
\hline Wuwei & 2 & $1,815,059$ & 33,249 & $\mathrm{~N} 37^{\circ} 55^{\prime} \mathrm{E} 102^{\circ} 38^{\prime}$ \\
\hline Baiyin & 2 & $1,708,752$ & 21,209 & $\mathrm{~N} 36^{\circ} 33^{\prime} \mathrm{E} 104^{\circ} 12^{\prime}$ \\
\hline Lanzhou & 5 & $3,616,163$ & 13,271 & $\mathrm{~N} 36^{\circ} 02^{\prime} \mathrm{E} 103^{\circ} 48^{\prime}$ \\
\hline Dinxi & 2 & $2,698,624$ & 19,609 & $\mathrm{~N} 35^{\circ} 34^{\prime} \mathrm{E} 104^{\circ} 37^{\prime}$ \\
\hline Pingliang & 2 & $2,068,033$ & 11,325 & $\mathrm{~N} 35^{\circ} 32^{\prime} \mathrm{E} 106^{\circ} 41^{\prime}$ \\
\hline Qingyang & 3 & $2,211,191$ & 27,119 & $\mathrm{~N} 35^{\circ} 44^{\prime} \mathrm{E} 107^{\circ} 37^{\prime}$ \\
\hline Tianshui & 3 & $3,262,549$ & 14,392 & $\mathrm{~N} 34^{\circ} 35^{\prime} \mathrm{E} 105^{\circ} 44^{\prime}$ \\
\hline Longnan & 2 & $2,567,718$ & 27,923 & $\mathrm{~N} 33^{\circ} 24^{\prime} \mathrm{E} 104^{\circ} 55^{\prime}$ \\
\hline
\end{tabular}

Note. *: Total population of the administrative region. 


\section{Results}

\subsection{Summer-time air quality overview}

Figures 2 and 3 show the mass concentration indicators $\mathrm{PM}_{2.5}$ and $\mathrm{PM}_{10}, \mathrm{CO}, \mathrm{NO}_{2}, \mathrm{SO}_{2}$ and 8-hr peak $\mathrm{O}_{3}$ values for the entire study period (1 June-31 August 2015) in the study area. Average $\mathrm{PM}_{2.5}$ concentrations in the province were not high with an average concentration of $25-28 \mu \mathrm{g} / \mathrm{m}^{3}$ in all cities except for Lanzhou and Pingliang, where the average concentrations of $\mathrm{PM}_{2.5}$ exceeded $35 \mu \mathrm{g} / \mathrm{m}^{3}$. Minimum concentrations were observed in the southern part of the province where the concentration was $16 \mu \mathrm{g} / \mathrm{m}^{3}$ (Tianshui). $\mathrm{PM}_{10}$ displayed analogous spatial pattern. $\mathrm{PM}_{10}$ concentrations varied from 50 to $70 \mu \mathrm{g} / \mathrm{m}^{3}$ in most cities, and was $100 \mu \mathrm{g} / \mathrm{m}^{3}$ in Lanzhou city. The gaseous pollutants $\left(\mathrm{CO}, \mathrm{SO}_{2}\right.$, $\left.\mathrm{NO}_{2}, \mathrm{O}_{3}\right)$ demonstrated varied spatial allocation. Exceeded levels of $\mathrm{NO}_{2}$ were observed in Lanzhou and Pingliang with 42.59 and $40.8 \mu \mathrm{g} / \mathrm{m}^{3}$, respectively; the high concentration of $\mathrm{NO}_{2}$ is associated with a well-developed coal industry in Pingliang, and chemical and petrochemical industry in Lanzhou. Increased concentrations of $\mathrm{NO}_{2}$ in Lanzhou is associated with a large number of exhaust emissions from cars and rail transport, as the city is a major transportation center in the northwest of China. The levels of $\mathrm{SO}_{2}$ in the summer months were not high, with an average of $12 \mu \mathrm{g} / \mathrm{m}^{3}$, except for Baiyin and Jinchang cities with the highest $\mathrm{SO}_{2}$ that exceeded the NAAQS standards Grade 1 (35.06 and $26.34 \mu \mathrm{g} / \mathrm{m}^{3}$, respectively). Concentration levels of $\mathrm{O}_{3}$ did not exceed specified levels of pollution with an average of $58 \pm 15 \mu \mathrm{g} / \mathrm{m}^{3}$ for the province. In general, gaseous pollutants showed no high effect in almost all cities of Gansu Province. The concentrations of pollutants in all towns of studied area in summer are shown in table 2 .

\subsection{Spatial variability}

Spatial variability was measured using Pearson's linear correlation analysis between the cities of the region in order to study the regional correlations of PM pollution indicators. The correlation coefficient $(r)$ of daily average $\mathrm{PM}_{10}$ and $\mathrm{PM}_{2.5}$ between all the studied cities in the province are shown in table 2 . The correlation coefficient $0.000-0.299$ was accepted as a weak correlation, $0.300-0.499$ as a moderate correlation, and $0.500-1.000$ as a strong
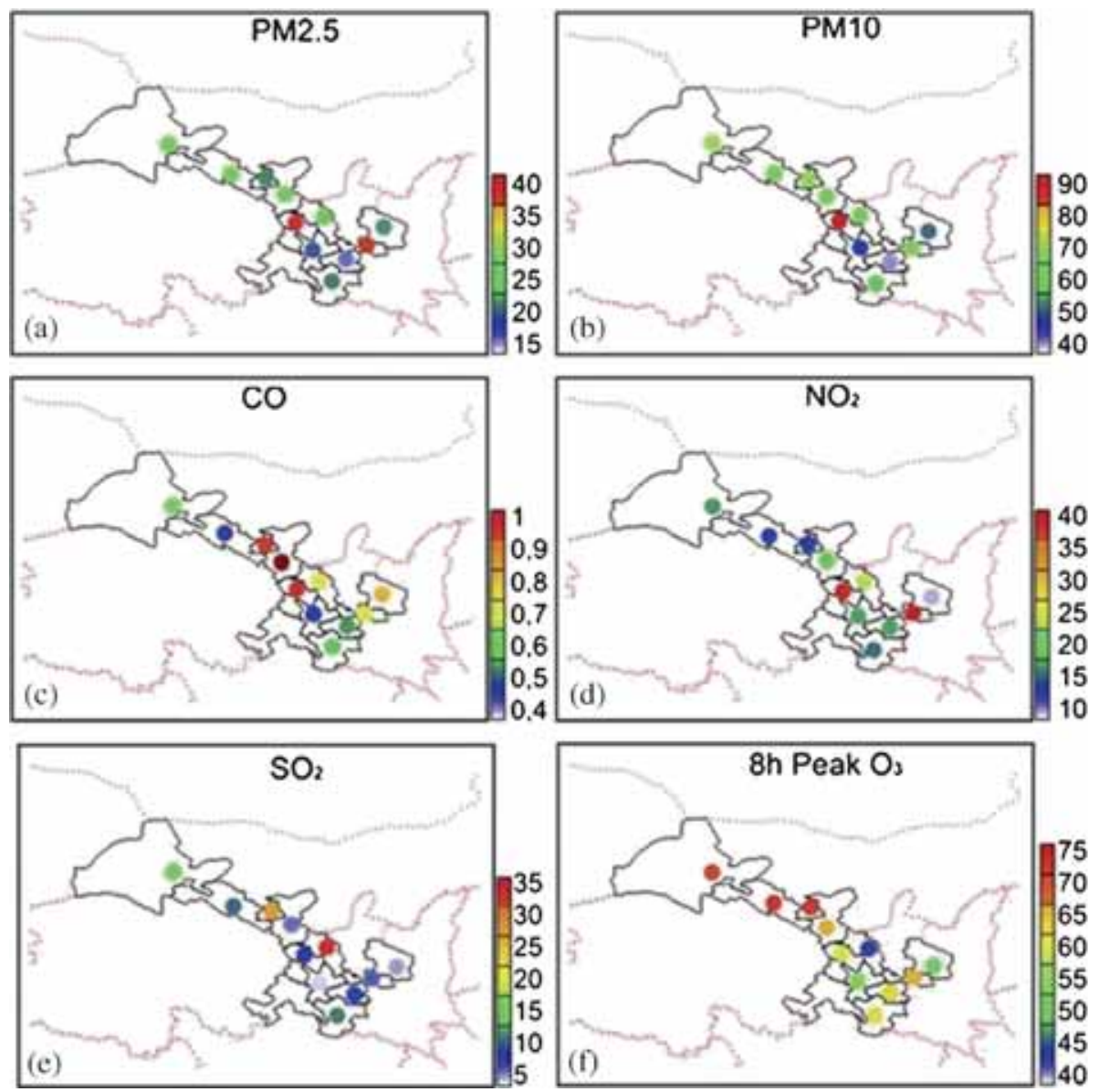

Figure 2. Summer-time concentrations of (a) $\mathrm{PM}_{2.5}$, (b) $\mathrm{PM}_{10}$, (c) $\mathrm{CO}$, (d) $\mathrm{NO}_{2}$, (e) $\mathrm{SO}_{2}$, and (f) 8-hr peak $\mathrm{O}_{3}$. 
correlation, -0.001 to -0.300 as a weak negative correlation. Table 3 shows that most of the pairs of cities presented moderate and strong correlation. The correlation between Lanzhou and Baiying and Dingxi $\left(r=0.479\right.$ for $\mathrm{PM}_{2.5}, r=0.831$ for $\mathrm{PM}_{10}$ between Lanzhou and Baiying; $r=0.475$ for $\mathrm{PM}_{2.5}$ and $r=0.708$ for $\mathrm{PM}_{10}$ between Lanzhou and Dingxi; $r=0.653$ for $\mathrm{PM}_{2.5}$ and $r=0.743$ for $\mathrm{PM}_{10}$ between Baiying with Dingxi), and between
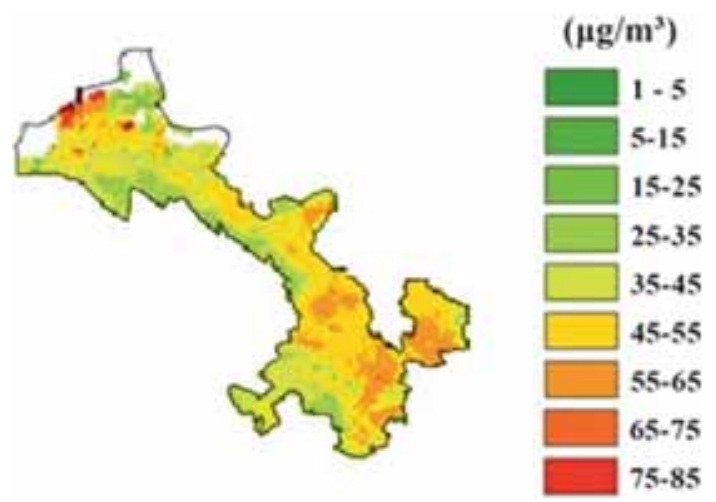

Figure 3. The concentration of $\mathrm{PM}_{2.5}$ in Gansu Province.
Jiayuguan and Zhangye and Wuwei $(r=0.535$ for $\mathrm{PM}_{2.5}, r=0.667$ for $\mathrm{PM}_{10}$ between Jiayuguan and Zhangye; $r=0.743$ for $\mathrm{PM}_{2.5}, r=0.772$ for $\mathrm{PM}_{10}$ between Jiayuguan and Wuwei; $r=0.729$ for $\mathrm{PM}_{2.5}$, $r=0.817$ for $\mathrm{PM}_{10}$ between Zhangye with Wuwei). This indicates that a significant proportion of $\mathrm{PM}_{2.5}$ in urban areas was presented as secondary organic aerosol, such as ammonium sulfate $\left(\left(\mathrm{NH}_{4}\right)_{2} \mathrm{SO}_{4}\right)$, or fugitive dust, which has a broader distribution among the region than just the primary anthropogenic pollutant. Weak negative correlation was observed between pairs of cities Longnan and Jinchang $\left(r=-0.1\right.$ for $\mathrm{PM}_{2.5}, r=-0.036$ for $\left.\mathrm{PM}_{10}\right)$, located $620 \mathrm{~km}$ from each other. The correlation coefficient for $\mathrm{PM}_{10}$, as a rule, was higher as compared to $\mathrm{PM}_{2.5}$. However, there are some factors that may influence concentration of $\mathrm{PM}_{2.5}$ in urban areas, including: (1) local sources of primary PM; (2) topographical barriers between cities; (3) indicators processing period; (4) meteorological phenomena; and (5) differences in the behaviour of semi-volatile components (Sheppard et al. 2001). Cities located closer to each presented with higher correlations.

Table 2. Summer average concentrations in studied cities.

\begin{tabular}{|c|c|c|c|c|c|c|}
\hline City & $\begin{array}{c}\mathrm{PM}_{2.5} \\
\left(\mu \mathrm{g} / \mathrm{m}^{3}\right)\end{array}$ & $\begin{array}{c}\mathrm{PM}_{10} \\
\left(\mu \mathrm{g} / \mathrm{m}^{3}\right)\end{array}$ & $\begin{array}{c}\mathrm{CO} \\
\left(\mathrm{mg} / \mathrm{m}^{3}\right)\end{array}$ & $\begin{array}{c}\mathrm{NO}_{2} \\
\left(\mu \mathrm{g} / \mathrm{m}^{3}\right)\end{array}$ & $\begin{array}{c}\mathrm{SO}_{2} \\
\left(\mu \mathrm{g} / \mathrm{m}^{3}\right)\end{array}$ & $\begin{array}{c}\text { 8-hr } \\
\text { peak } \mathrm{O}_{3}\end{array}$ \\
\hline Jiayuguan & 26.53 & 78.26 & 0.68 & 20.61 & 18.25 & 70 \\
\hline Zhangye & 26.51 & 59.48 & 0.47 & 15.11 & 13.01 & 73 \\
\hline Jinchang & 21.4 & 72.5 & 0.93 & 15.14 & 26.34 & 73 \\
\hline Wuwei & 27.3 & 71.5 & 1.76 & 23.22 & 7.07 & 65 \\
\hline Baiyin & 25.32 & 70.76 & 0.74 & 25.73 & 35.06 & 44 \\
\hline Lanzhou & 38.8 & 98.8 & 0.94 & 42.59 & 11.34 & 58 \\
\hline Dinxi & 22.41 & 49.42 & 0.47 & 17.94 & 6.3 & 55 \\
\hline Pingliang & 36 & 71.42 & 0.74 & 40.8 & 8.6 & 65 \\
\hline Qingyang & 23.78 & 54.81 & 0.81 & 11.54 & 5.39 & 53 \\
\hline Tianshui & 16.41 & 40.37 & 0.57 & 18.15 & 9.4 & 63 \\
\hline Longnan & 24.9 & 61.13 & 0.60 & 18.42 & 13.06 & 65 \\
\hline
\end{tabular}

Table 3. Correlation coefficients for $P M_{2.5}$ and $P M_{10}$ between studied cities. *

\begin{tabular}{lllllllllllrr}
\hline & Jiayuguan & Zhangye & Jinchang & Wuwei & Baiyin & Lanzhou & Dinxi & Pingliang & Qingyang & Tianshui & Longnan \\
\hline Jiayuguan & & 0.103 & 0.1928 & 0.1228 & 0.0491 & 0.0862 & -0.017 & 0.0565 & -0.0193 & -0.054 & -0.1001 \\
Zhangye & 0.538 & & 0.5354 & 0.7433 & 0.3882 & 0.3743 & 0.2376 & 0.242 & -0.0181 & 0.068 & 0.0555 \\
Jinchang & 0.6392 & 0.6677 & & 0.7294 & 0.4138 & 0.1818 & 0.1654 & 0.096 & -0.0121 & 0.1235 & 0.0865 \\
Wuwei & 0.6282 & 0.7724 & 0.8174 & & 0.6629 & 0.3687 & 0.4495 & 0.0017 & -0.1071 & 0.096 & 0.2256 \\
Baiyin & 0.4397 & 0.6016 & 0.4855 & 0.669 & & 0.4798 & 0.6531 & -0.0932 & -0.0107 & 0.2434 & 0.159 \\
Lanzhou & 0.3312 & 0.5793 & 0.4148 & 0.5178 & 0.8311 & & 0.4755 & 0.17 & 0.225 & 0.2371 & 0.317 \\
Dinxi & 0.258 & 0.4908 & 0.3241 & 0.5251 & 0.7437 & 0.708 & & -0.1881 & -0.0281 & 0.2654 & 0.4014 \\
Pingliang & 0.0995 & 0.1866 & 0.1575 & 0.066 & 0.3023 & 0.4123 & 0.2353 & & 0.6041 & 0.3836 & 0.1239 \\
Qingyang & 0.0259 & 0.0285 & 0.1167 & 0.0595 & 0.2477 & 0.3398 & 0.2341 & 0.4454 & 0.364 & 0.5524 & 0.2895 \\
Tianshui & 0.0505 & 0.0604 & 0.1591 & 0.1109 & 0.3279 & 0.4116 & 0.353 & 0.3646 & 0.7543 & 0.6394 \\
Longnan & 0.0364 & 0.1007 & 0.0685 & 0.1001 & 0.2436 & 0.3028 & 0.2724 & 0.3249 & 0.4825 & 0.715 \\
\hline
\end{tabular}

Note. $*: \mathrm{PM}_{2.5}$ values are shown above diagonal; that of $\mathrm{PM}_{10}$ below diagonal. 
The correlation coefficients were compared taking into account the distance between cities. Strong and similar relation was detected among the $r$ values and the distance between the cities in the region. The results are shown in figure 4 . The correlation coefficient between the cities with distance of $250 \mathrm{~km}$ is 0.6 for $\mathrm{PM}_{2.5}$ and less than 0.7 for $\mathrm{PM}_{10}$ when the distance between the cities is more than $180 \mathrm{~km}$. The $\mathrm{PM}_{2.5} / \mathrm{PM}_{10}$ ratio in summer $R^{2}=$ $0.54, p<0.01$. This result of the relationship can be associated with climatic, geographic and geological conditions of the study area. The province has deserts in the north, a mountainous part in the center and plains in the south. All these affect the speed of particles movement in the atmosphere, especially dry air of the central and northern parts.

\subsection{Temporal variability}

\subsection{1 $P M_{2.5} / P M_{10}$ and meteorology variation}

Figure 5 illustrates the temporal variation of daily average $\mathrm{PM}_{2.5}$ and $\mathrm{PM}_{10}$ concentrations, wind speed, and temperature parameters in Lanzhou and Tianshui, the largest city in the province. A negative correlation was observed between the indicators of $\mathrm{PM}_{2.5}$ and the wind speed: usually high concentrations of $\mathrm{PM}_{2.5}$ were present during weaker winds, and lower concentrations of $\mathrm{PM}_{2.5}$ occurred with stronger winds. In general, there was no obvious relationship between detected $\mathrm{PM}_{2.5} / \mathrm{PM}_{10}$ and the air temperature. This relationship between $\mathrm{PM}_{2.5}$ concentrations and WS, $\mathrm{RH}$ and $\mathrm{T}$, will be demonstrated in further studies

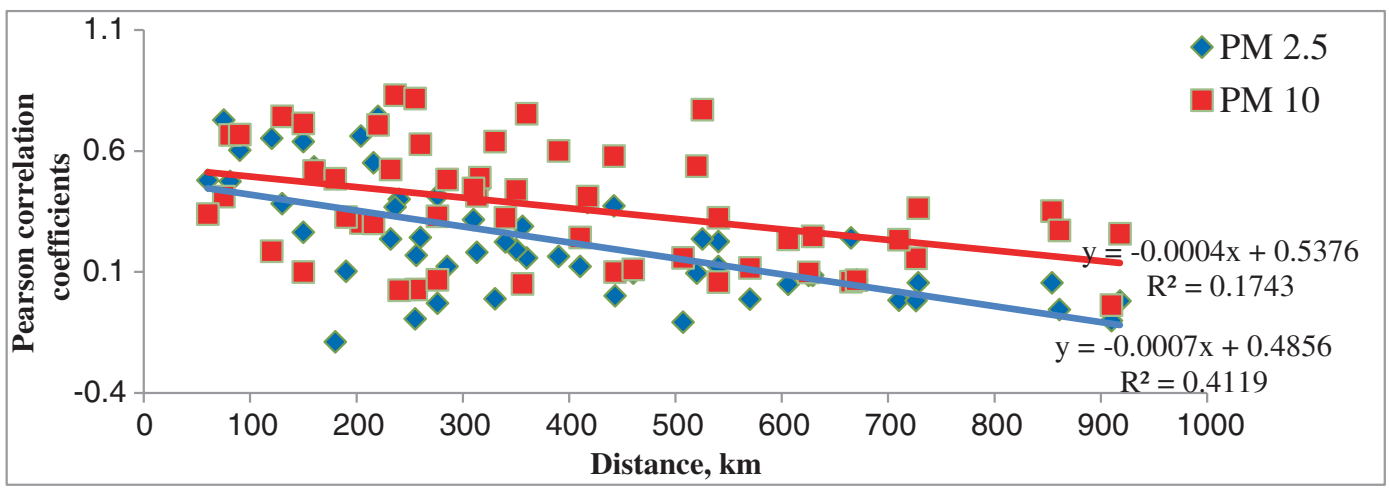

Figure 4. Pearson correlation coefficients for $\mathrm{PM}_{2.5}$ and $\mathrm{PM}_{10}$ between cities in the region.

Lanzhou

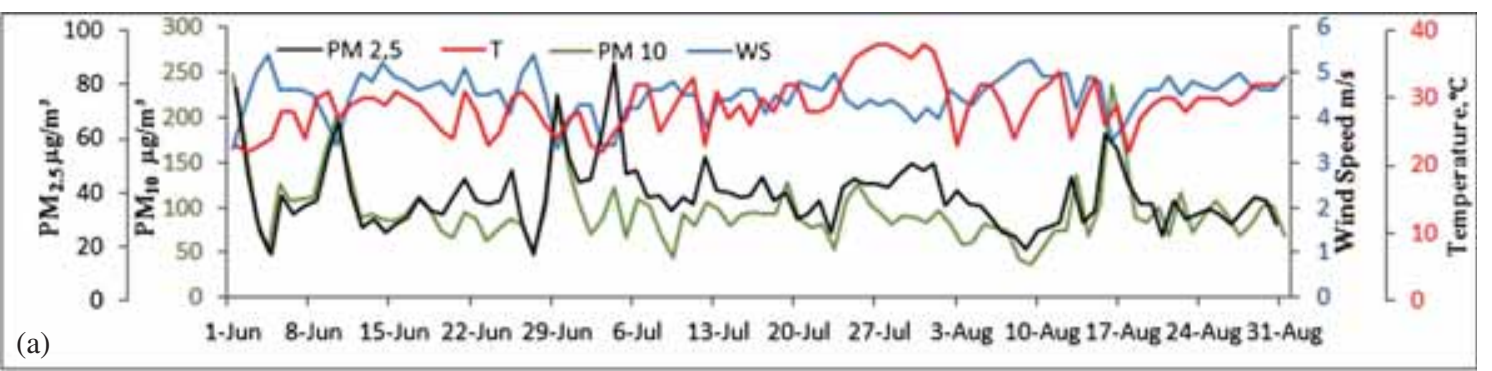

Tianshui

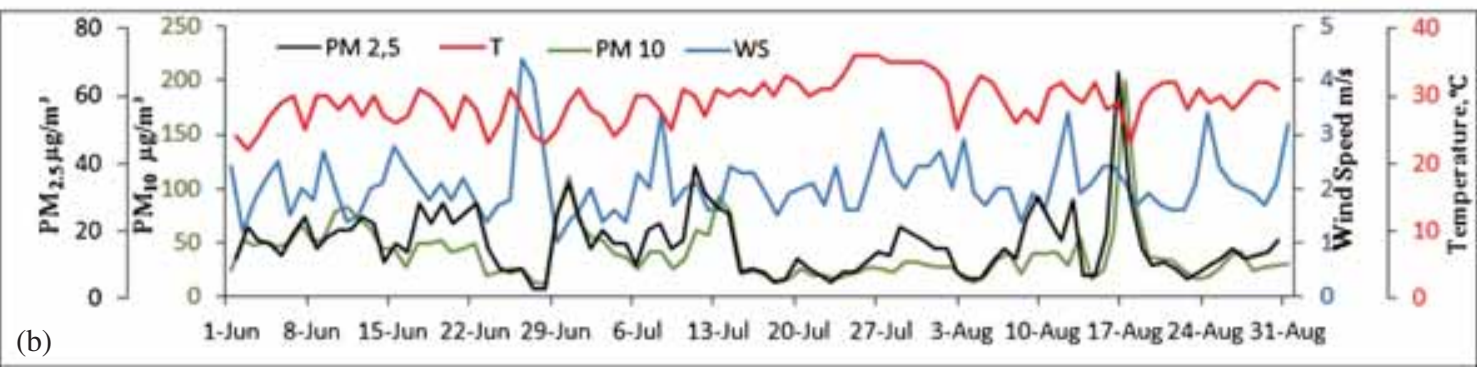

Figure 5. Daily $\mathrm{PM}_{2.5 / 10}$ concentrations, wind speed and temperature in summer 2015 in Lanzhou and Tianshui. 
using linear regression analysis for all the days in the summer period. In Lanzhou, some regression coefficients for $\mathrm{PM}_{2.5}$ is negative associated with wind speeds by a factor of -0.94 and -0.71 for $\mathrm{PM}_{10}$; also, the relationship between $\mathrm{PM}_{2.5}, \mathrm{PM}_{10}$ and air temperature showed weak negative correlation of -0.13 and -0.19 , but positively associated to relative humidity with a coefficient of 0.19 and 0.21 , respectively (table $4 \mathrm{~b}$ ). In Tianshui, the association between $\mathrm{PM}_{2.5}$ and three meteorological parameters was minimal, with the regression coefficient -0.007 that characterizes the small effect of temperature, wind speed and air humidity on the level of polluting particles in the atmosphere. Therefore, since Gansu Province has a transitional, from semi-dry to dry continental climate with warm and hot summer resulting in low wind speed, it is not the main factor for the dispersion of pollutants. Typically, stagnant conditions with wind speed less of $3 \mathrm{~m} / \mathrm{s}$, which lead to absorption of PM and other gaseous pollutants, are often observed in Lanzhou and have increased indicators of PM contamination.

Table 4. (a) $P M_{2.5} / P M_{10}$ ratio; (b) correlation coefficients between mass concentrations of PM 2.5 and $P M_{10}$ and average meteorological factors: air temperature $(T)$, wind speed (WS) and relative humidity $(R H)$.

\begin{tabular}{|c|c|c|c|c|c|c|c|c|c|c|c|}
\hline \multirow[t]{2}{*}{ (a) } & \multirow[b]{2}{*}{ June } & \multirow[b]{2}{*}{ July } & \multirow[b]{2}{*}{ August } & \multirow[b]{2}{*}{ Episode } & \multirow[b]{2}{*}{ Non-episode } & \multicolumn{3}{|l|}{ (b) } & \multicolumn{3}{|c|}{$\mathrm{PM}_{10}$} \\
\hline & & & & & & $\mathrm{T}$ & WS & $\mathrm{RH}$ & $\mathrm{T}$ & WS & $\mathrm{RH}$ \\
\hline Jiayuguan & 0.312 & 0.442 & 0.305 & 0.283 & 0.29 & -0.01 & 0.07 & -0.09 & 0.02 & 0.12 & -0.12 \\
\hline Zhangye & 0.439 & 0.45 & 0.441 & 0.39 & 0.624 & -0.35 & -0.22 & 0.09 & -0.34 & -0.19 & -0.39 \\
\hline Jinchang & 0.32 & 0.294 & 0.271 & 0.262 & 0.359 & 0.22 & 0.17 & 0.26 & 0.12 & 0.31 & 0.11 \\
\hline Wuwei & 0.442 & 0.381 & 0.343 & 0.404 & 0.41 & -0.12 & -0.26 & -0.16 & -0.10 & -0.26 & 0.09 \\
\hline Baiyin & 0.348 & 0.369 & 0.362 & 0.325 & 0.408 & -0.14 & -0.43 & -0.11 & -0.18 & -0.44 & -0.27 \\
\hline Lanzhou & 0.352 & 0.475 & 0.386 & 0.319 & 0.469 & -0.13 & -0.94 & 0.19 & -0.12 & -0.71 & -0.21 \\
\hline Dinxi & 0.419 & 0.474 & 0.472 & 0.384 & 0.448 & -0.12 & -0.36 & 0.05 & -0.23 & -0.15 & 0.29 \\
\hline Pingliang & 0.434 & 0.6 & 0.487 & 0.382 & 0.613 & -0.21 & -0.04 & 0.35 & -0.27 & -0.20 & 0.22 \\
\hline Qingyang & 0.393 & 0.485 & 0.424 & 0.376 & 0.508 & -0.03 & -0.01 & 0.15 & 0.00 & 0.12 & -0.05 \\
\hline Tianshui & 0.375 & 0.435 & 0.423 & 0.344 & 0.435 & -0.15 & -0.16 & 0.13 & -0.17 & -0.21 & 0.04 \\
\hline Longnan & 0.305 & 0.448 & 0.476 & 0.38 & 0.434 & -0.2 & 0.12 & 0.08 & -0.11 & 0.16 & -0.12 \\
\hline
\end{tabular}
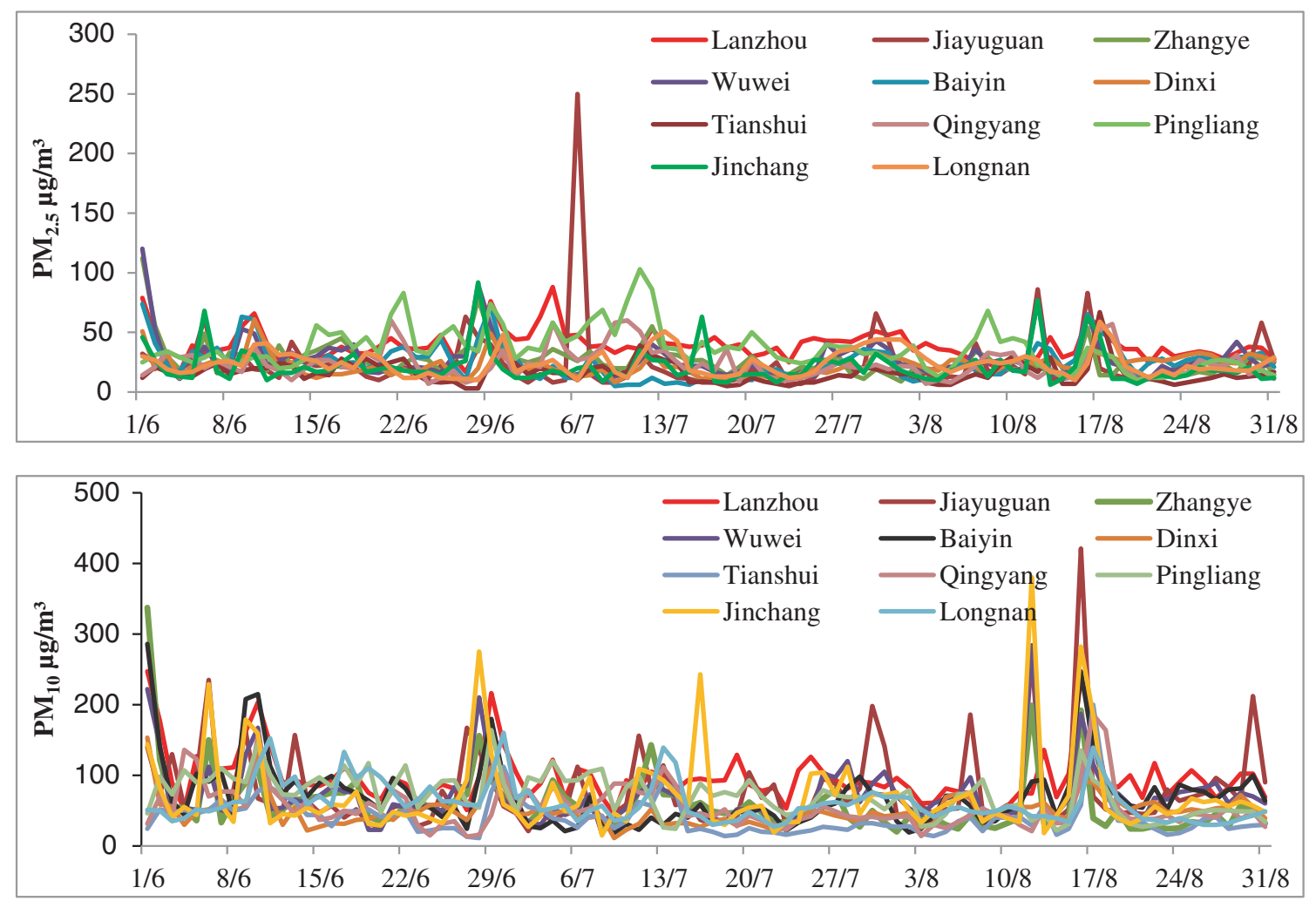

Figure 6. Concentration of $\mathrm{PM}_{2.5}$ and $\mathrm{PM}_{10}$ in the cities of Gansu Province (summer 2015). 


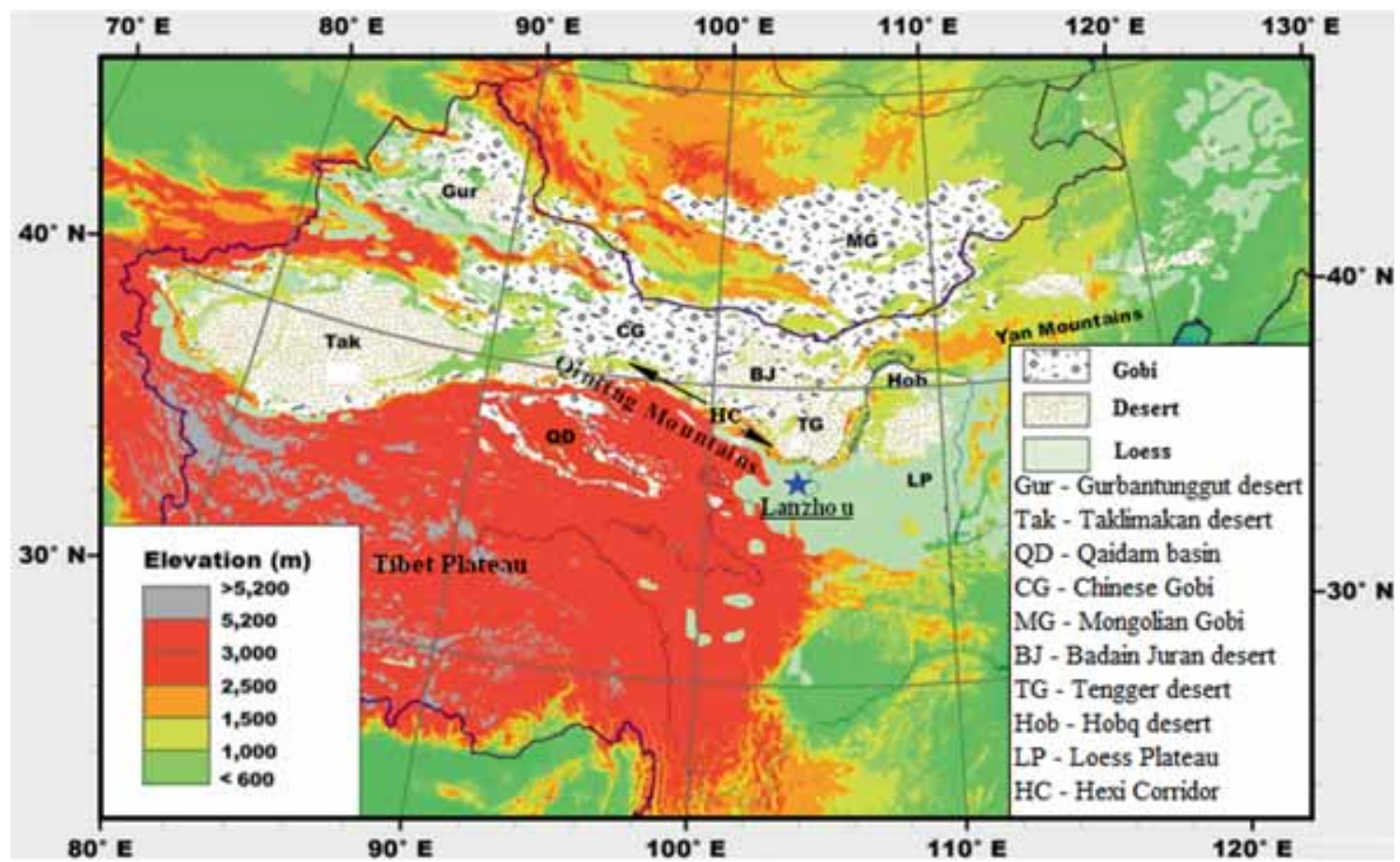

Figure 7. Distributions of nine major deserts and elevation distribution in northern and northwestern China.

\subsubsection{Concentration $P M_{2.5}$ and $P M_{10}$ on episode and non-episode days}

Figure 6 shows the concentration of $\mathrm{PM}_{2.5}$ and $\mathrm{PM}_{10}$ particles in all cities of the study area. Episode days and non-episodes days were of irregular occurrence in the cities of the province, therefore, maximum peaks were observed in cities with well-developed non-ferrous metallurgy - Lanzhou, Wuwei, (88 and $120 \mu \mathrm{g} / \mathrm{m}^{3}$ for $\mathrm{PM}_{2.5}$, respectively). In one day in Jiayuguan, there was an unusual index growth of $\mathrm{PM}_{2.5}$ up to $250 \mu \mathrm{g} / \mathrm{m}^{3}$ for this region. The average concentration of $\mathrm{PM}_{2.5}$ in all episode days was between 80 and $100 \mu \mathrm{g} / \mathrm{m}^{3}$, which is much higher than the concentrations of $\mathrm{PM}_{2.5}$ in non-episode days $\left(15-20 \mu \mathrm{g} / \mathrm{m}^{3}\right)$.

$\mathrm{PM}_{10}$ indicator for episode days took place almost simultaneously in all the cities of Gansu Province. Figure 6 shows that $\mathrm{PM}_{10}$ is clearly expressed for eight episode days: June 1-2, June 9-10, June 28-29, and August 16-17. The average concentration of $\mathrm{PM}_{10}$ in episode days was 200 and $30-40 \mu \mathrm{g} / \mathrm{m}^{3}$ in the non-episode day. Nonepisode days were also evenly distributed throughout the study.

According to previous studies, one of the main sources of air pollution with PM indicators are dust storms characterized by high $\mathrm{PM}_{10}$ concentrations and relatively low concentrations of $\mathrm{PM}_{2.5}$ due to the invasion of large particles; the $\mathrm{PM}_{2.5} / \mathrm{PM}_{10}$ ratio has decreased on the whole. Thus, the $\mathrm{PM}_{2.5} /$ $\mathrm{PM}_{10}$ ratio may be used as a key measurement to determine the sources of dust (Zhang et al. 1998).
The monthly average $\mathrm{PM}_{2.5} / \mathrm{PM}_{10}$ ratio in the cities of the province was $0.405(0.271-0.487)$, low coefficients of $\mathrm{PM}_{2.5} / \mathrm{PM}_{10}$ indicate the increase in dust and aerosols (table 4a).

The $\mathrm{PM}_{2.5} / \mathrm{PM}_{10}$ ratio for cities in the episode day varies from 0.262 in the city of Jinchang to 0.404 in Wuwei, which indicated the predominance of primary sources of PM pollution. For non-episode days, the $\mathrm{PM}_{2.5} / \mathrm{PM}_{10}$ ratio showed low change towards indices in Pingliang 0.613 and 0.382 in non-episode days, Zhangye 0.624 and 0.39 , respectively, which included both primary and secondary pollution sources.

\subsubsection{Long-range transport of dust in Gansu}

Tracking sources and contaminant pathways in the Gansu Province trajectories were calculated using the Hybrid Single Particle Lagrangian Integrated Trajectory Model (HYSPLIT) developed by Air Resources Laboratory (ARL) in the National Oceanic and Atmospheric Administration (NOAA).72-hr backward trajectories were utilized, starting at 100, 500, and $1000 \mathrm{~m}$. Zhang et al. (1998) found that Asian particles had originated from two regions in China: deserts in northern and northwestern China (Taklimakan Desert and Badain Juran Desert (figure 7)). In general, we can distinguish between three trajectories that were selected above cities of Gansu Province. (1) 'North', which is associated with air masses passing through the Gobi Desert, Republic of Mongolia, and Inner Mongolia (figure 8b, d, e, f). (2) 'North-West', 
NOAA HYSPUT MODEL

(a) Backward trajectories ending at 1200 UTC 01 Jun 15 GDAS Meteorological Data

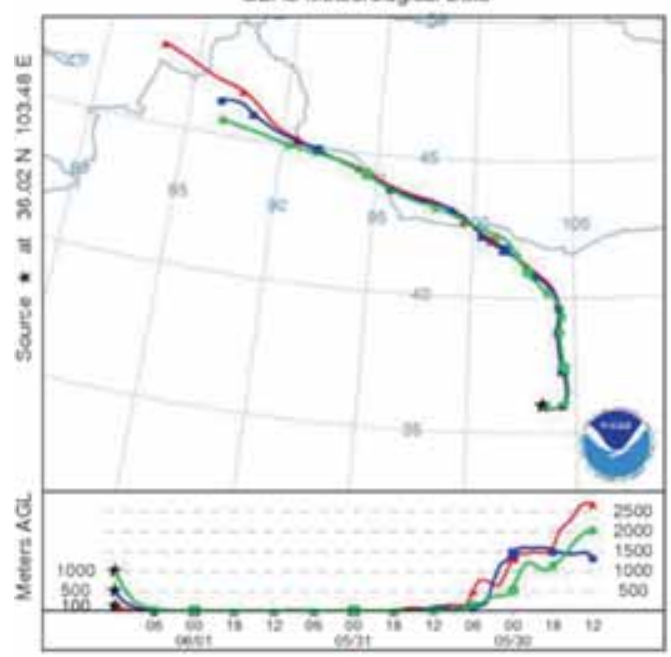

NOAA HYSPUT MOOEL

(c) Backward trajectories ending at 1200 UTC 27 Jun 15 GDAS Meleorological Dati

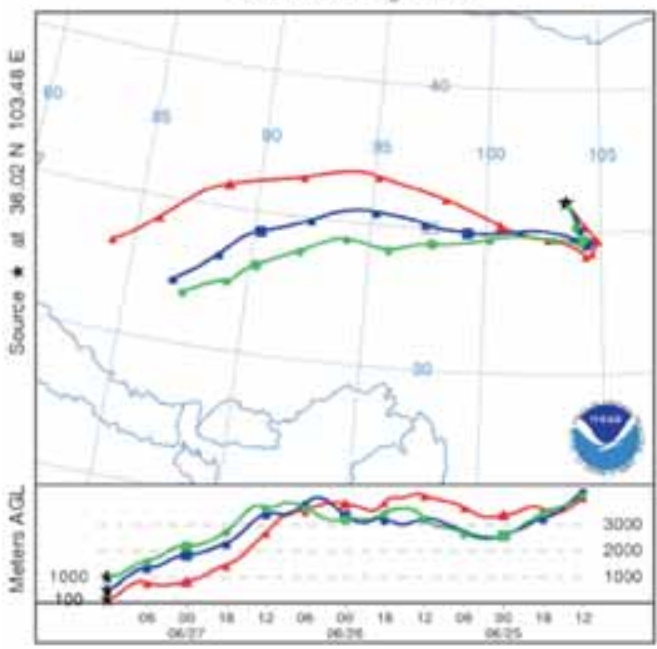

NOAA HYSPUT MOOEL

(c) Backward trajectories ending at 1200 UTC 10 Jul 15 GDAS Meseorological Data

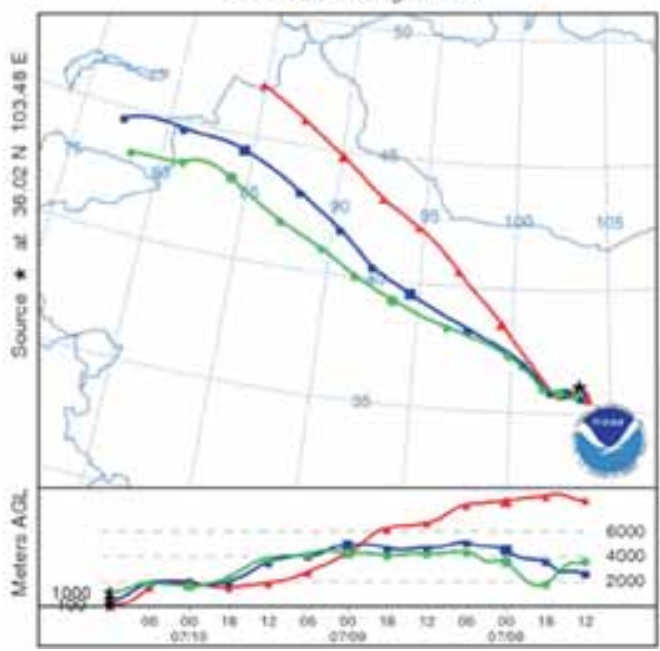

NOAA HYSPUT YODEL

(b) Backward trajectories ending at 1200 UTC 08 Jun 15 GDAS Metecrobogical Data

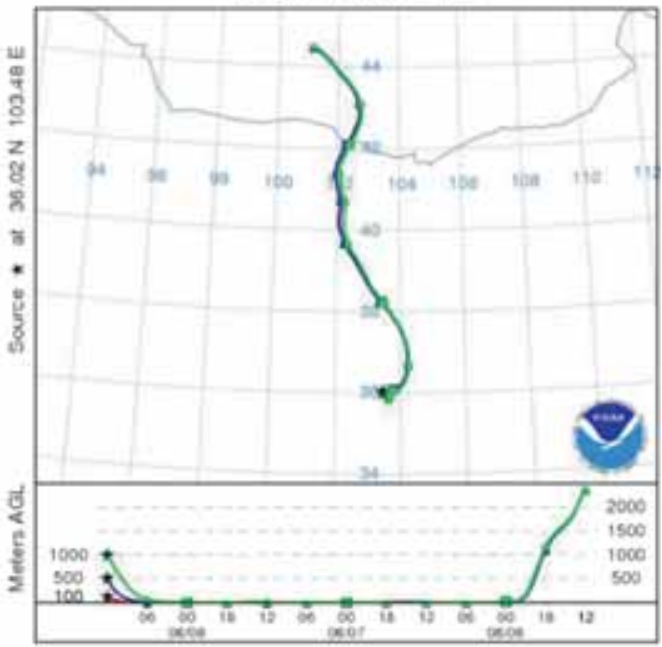

NOAA HYSPUT MODEL

(d) Backward trajectories ending at 1200 UTC 28 Jun 15 GDAS Motecroiogical Data

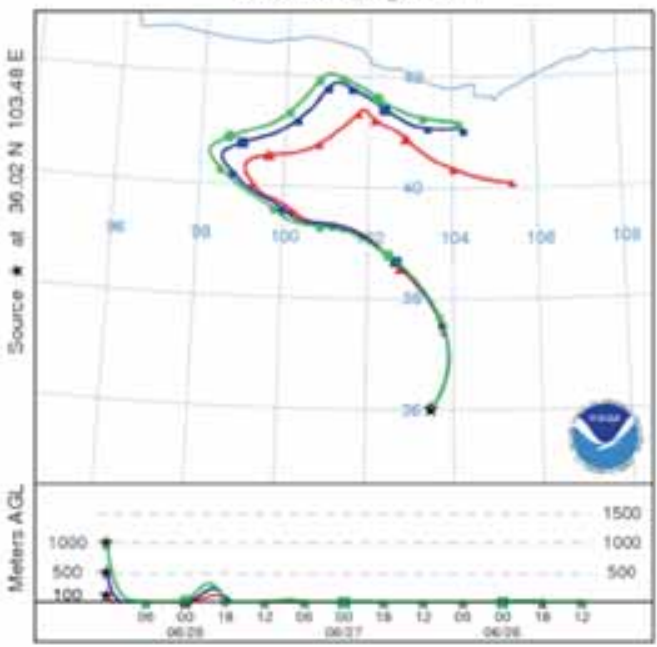

NOAA HYSPII MODE

(f) Backward trajectories onding at 1200 UTC o1 Aug 15 GDAS Meteorological Data

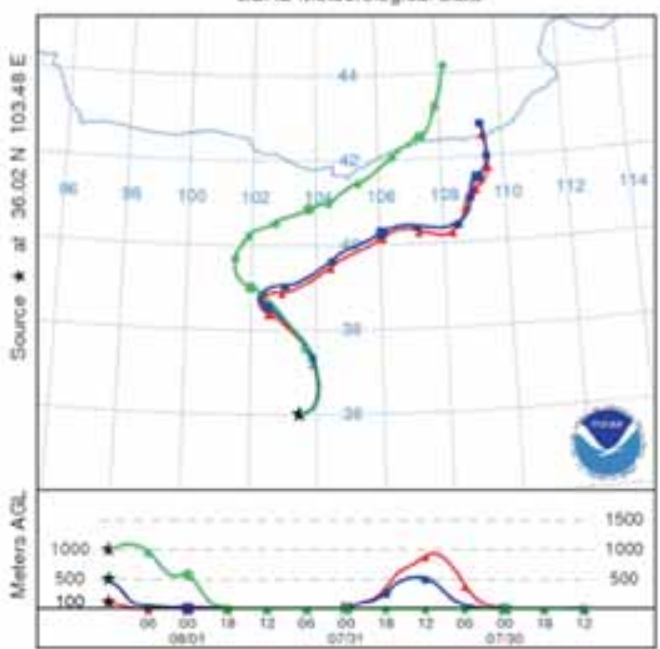

Figure 8. 72-hr backward trajectories starting at three altitudes of 100, 500 and $1000 \mathrm{~m}$ in Lanzhou. (a) 12:00 am June 1*, (b) 12:00 am June $8^{* *}$, (c) 12:00 am June 27**, (d) 12:00 am June 28*, (e) 12:00 am July 10**, (f) 12:00 am August $1^{* *}$. Note. *: Episode day; **: Non-episode day. 
appearing mainly in the northwestern part of Xinjiang (Gurbantunggut Desert), where air mass go through Inner Mongolia and Ningxia to Lanzhou city (figure 8a, b). (3) 'Western', which originated in the western deserts (Taklimakan desert in Xinjiang) and in the desert of Qaidam basin, where air masses pass through the Tibetan Plateau and Qinghai (figure 8c).

Despite the different ways of dust passage in the Gansu Province, they showed similar features. Large part of air masses penetrated into the province mainly from the north direction, except for air

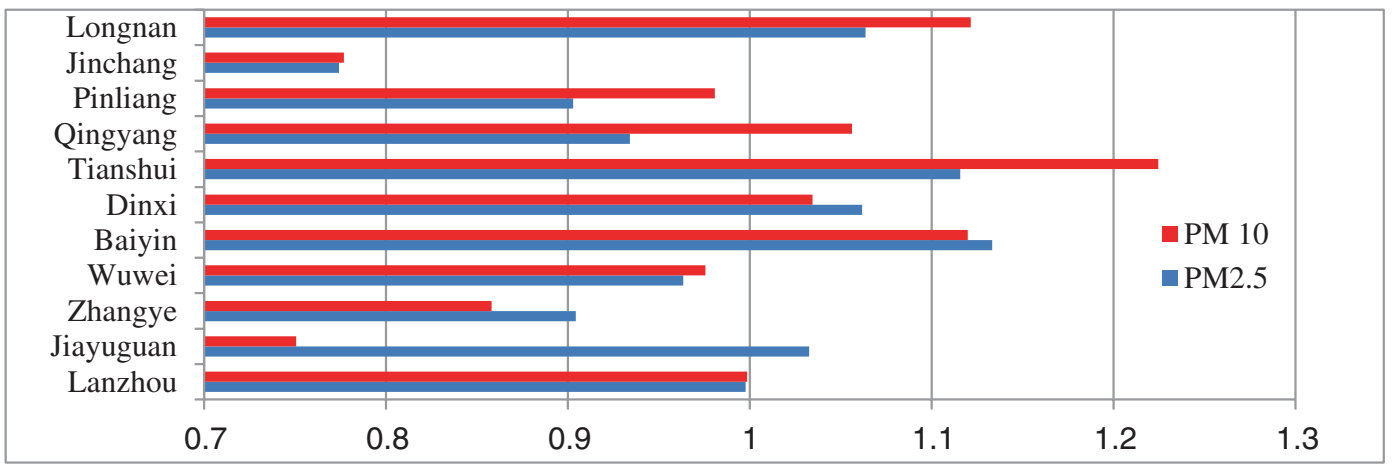

Figure 9. Weekday/weekend $\mathrm{PM}_{2.5}$ and $\mathrm{PM}_{10}$ ratios in every city of the region.
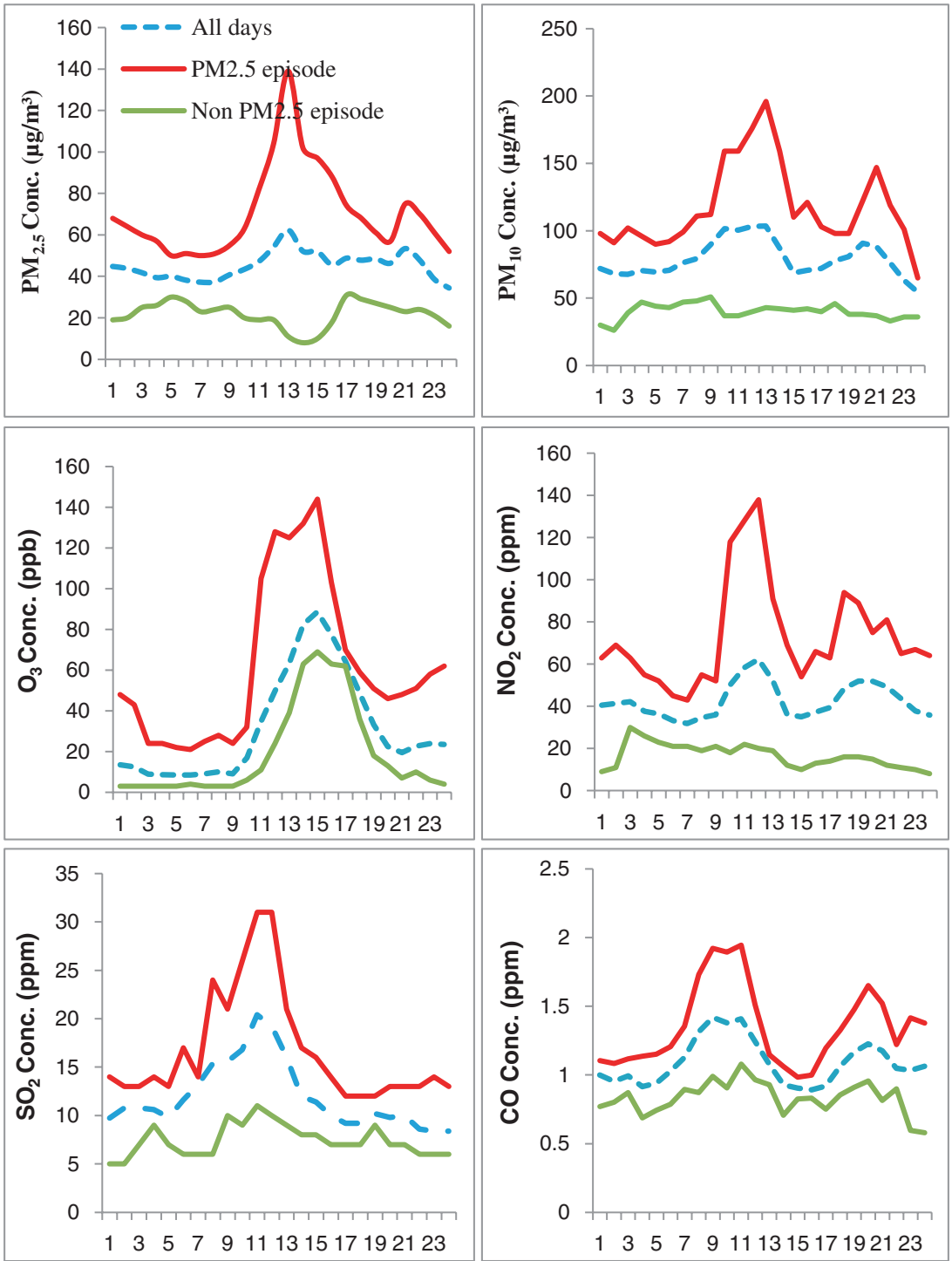

Figure 10. Diurnal changes of $\mathrm{PM}_{2.5}, \mathrm{PM}_{10}, \mathrm{O}_{3}, \mathrm{NO}_{2}, \mathrm{SO}_{2}$ and $\mathrm{CO}$ in the episode and non-episode days in Lanzhou. 
masses from the Tibetan plateau, although the air passage was mainly from the north-west and north-east directions. Figure 7 displays Hexi Corridor (Gansu Corridor), which stretches within $1000 \mathrm{~km}$ from the north-west (from the central part of Gansu, to Jiayuguan and Dunhuang), stretches along the northeastern foothills of the Qinling mountains with an altitude of over $3000 \mathrm{~m}$. The width of the corridor is from 20 to $100 \mathrm{~km}$, the altitude from $800 \mathrm{~m}$ in the west to $1500 \mathrm{~m}$ in the east. Air masses moving from the Gobi Desert and deserts of provinces, bump into high Qinling mountains and change their direction to Hexi Corridor, grabbing dusty desert air, which is characterized by presence of ground-level air masses (figure 8a,b,e,f). Another feature was the elevation of air masses during its transport. Figure 8(c and d) shows that air masses were more than $3000 \mathrm{~m}$ above ground and were carried to the upper atmosphere for long distances before reaching Lanzhou, with gradual lowering. The height level was mainly associated with a unique landscape of Taklimakan Desert and hilly Tibet Plateau, which gradually declined from over 4000 to $1800 \mathrm{~m}$ as it enters the city of Lanzhou.

\subsubsection{Weekday and weekend difference, diurnal changes}

Differences in concentration of pollutants in the atmosphere in the weekdays/weekends relationships have been investigated in many places for many years (Graedel et al. 1977; Marr and Harley 2002; Qin et al. 2004; Jones et al. 2008). Figure 9 shows the weekday/weekend $\mathrm{PM}_{2.5}$ and $\mathrm{PM}_{10}$ ratios in all cities in this study. The concentrations of $\mathrm{PM}_{2.5}$ and $\mathrm{PM}_{10}$ in studied cities showed minor differences between weekdays and weekends, at a ratio of the week/weekend with a difference of \pm 0.1 with a coefficient of 1 . Small changes of 0.9-1.1 were found for the gaseous pollutants and in rare cases exceeded 1.2.

Diurnal changes of $\mathrm{PM}_{2.5 / 10}, \mathrm{O}_{3}, \mathrm{SO}_{2}, \mathrm{NO}_{2}$, and $\mathrm{CO}$ in the periods of episode and non-episode days were studied in Lanzhou and are shown in figure 10. In Lanzhou, $\mathrm{PM}_{2.5}$ and $\mathrm{PM}_{10}$ showed high concentrations and stronger diurnal changes during episode days. On episode days, both $\mathrm{PM}_{2.5}$ and $\mathrm{PM}_{10}$ started to increase rapidly at $7-8 \mathrm{am}$ local time with an hourly rate of $15 \mu \mathrm{g} / \mathrm{m}^{3}$ for 5-6 hrs and reached peak concentration of $\sim 140$ $\mu \mathrm{g} / \mathrm{m}^{3}$ at mid-day. The concentration of both indicators in the afternoon began to deccrease slowly and at $8 \mathrm{pm}$, there was a sharp increase of concentrations: $\mathrm{PM}_{2.5}$ from 55 to $75 \mu \mathrm{g} / \mathrm{m}^{3}$ and $\mathrm{PM}_{10}$ from 100 to $125 \mu \mathrm{g} / \mathrm{m}^{3}$, following with concentration decline until midnight. This indicates that the emergence of carbon particles in Lanzhou is derived from common sources of emissions, such as automobile exhaust and industrial emissions, which are characterized by elevated concentrations of $\mathrm{PM}_{10}$ indicators. $\mathrm{O}_{3}$ is present in a high level of concentration and diurnal variation in the episode and non-episode days, with a maximum concentration of $144 \mu \mathrm{g} / \mathrm{m}^{3}$. Also, significant differences were found in the concentrations of daily changes in the episode and the non-episode days. A large distinction in the diurnal variation was observed in concentration of $\mathrm{NO}_{2}, \mathrm{SO}_{2}$, and $\mathrm{CO}$, performance variations in the daily course of the day showed high concentration in episode days. Increase in concentration of all the indicators occured relatively in parallel: from 7-8 am to peak concentration at $1 \mathrm{pm}$. The above analysis makes it clear that Lanzhou experiences high levels of $\mathrm{PM}_{2.5}, \mathrm{PM}_{10}$ and diurnal variations, therefore, the difference of $\mathrm{O}_{3}, \mathrm{NO}_{2}$ and additional particles must be further explored.

\section{Conclusion}

The concentration of pollutants in Gansu Province between June 1 and August 31 in 2015 was received based on monitoring of air quality from Ministry of Environmental Protection of the People's Republic of China. The results showed that:

1. Average PM concentrations in region exceeded the World Health Organization guideline values, which indicated serious impact on humans and the environment in Gansu Province.

2. The PM pollution is much more severe in China than those in USA and Europe.

3. Studies have shown that $20 \%$ of all summer days had higher concentration of $\mathrm{PM}_{2.5}$, exceeding NAAQS Grade I and II standards, and 33\% of days were for $\mathrm{PM}_{10}$. $\mathrm{PM}_{10}$ concentrations were practically similar for all studied cities and varied in the range of $60-70 \mu \mathrm{g} / \mathrm{m}^{3}$; it was indicated that PM pollution was a regional problem.

4. Apart from local pollution sources, there are external sources of pollution located outside the study area associated with passage of contaminants from elevated and desert regions of western and northern China.

5. The previous studies being compared, it can be assumed that atmospheric concentrations of pollutants gradually decreased, but are still at a high level.

6 . There is no clear distinction between working days and holidays in the concentrations of seven pollutants that indicate a weak influence of weekly human activities.

To get more detailed and accurate information, as well as to identify patterns of distribution of 
substance concentration in the atmosphere of cities in Gansu Province, a more detailed investigation of the area for a long period (all seasons) is needed.

\section{Acknowledgements}

This work was financially supported by the National Natural Science Foundation of China (No. 41371435), the Specialized Research Fund for the Doctoral Program of Higher Education of China (No. 20136204110003), and the Youth Science Foundation of Lanzhou Jiaotong University (No. 2013015).

\section{References}

An X, Zuo H and Chen L 2007 Atmospheric environmental capacity of $\mathrm{SO}_{2}$ in winter over Lanzhou in China: A case study; Adv. Atmos. Sci. 24 688-699.

Breiman L and Friedman J H 1985 Estimating optimal transformations for multiple regression and correlation; J. Am. Stat. Assoc. 80(391) 580-598.

Charron A and Harrison R M 2005 Fine $\left(\mathrm{PM}_{2.5}\right)$ and coarse $\left(\mathrm{PM}_{2.5-10}\right)$ particulate matter on a heavily trafficked London highway: Sources and processes; Environ. Sci. Technol. 39(20) 7768-7776.

Charron A, Harrison R M, Moorcroft S and Booker J 2004 Quantitative interpretation of divergence between $\mathrm{PM}_{10}$ and $\mathrm{PM}_{2.5}$ mass measurement by TEOM and gravimetric (Partisol) instruments; Atmos. Environ. 38(3) 415-423.

Choi Y S, Ho C H, Chen D, Noh Y H and Song C K 2008 Spectral analysis of weekly variation in $\mathrm{PM}_{10}$ mass concentration and meteorological conditions over China; Atmos. Environ. 42(4) 655-666.

Chu P C, Chen Y and Lu S 2008a Atmospheric effects on winter $\mathrm{SO}_{2}$ pollution in Lanzhou, China; Atmos. Res. 89(4) 365-373.

Chu P C, Chen Y, Lu S, Li Z and Lu Y 2008b Particulate air pollution in Lanzhou, China; Environ. Int. 34(5) 698-713.

Fan Q, Shen C, Wang X, Li Y, Huang W, Liang G and Huang Z 2013 Impact of a dust storm on characteristics of particle matter (PM) in Guangzhou, China; Asia-Pac. J. Atmos. Sci. 49(1) 121-131.

Fan J, Yue X, Jing Y, Chen Q and Wang S 2014 Online monitoring of water-soluble ionic composition of $\mathrm{PM}_{10}$ during early summer over Lanzhou city; J. Environ. Sci. 26(2) 353-361.

Fang J, Zhao C and Zhu W 2014 Concentration monitoring of $\mathrm{PM}_{2.5}$ and its forecast model during the heating period in Lanzhou; Environ. Sci. Technol. 37(4) 80-84.

Feng Y, Chen Y, Guo H, Zhi G, Xiong S, Li J and Fu J 2009 Characteristics of organic and elemental carbon in $\mathrm{PM}_{2.5}$ samples in Shanghai, China; Atmos. Res. 92(4) 434-442.

Graedel T E, Farrow L A and Weber T A 1977 Photochemistry of the 'Sunday Effect'; Environ. Sci. Technol. 11(7) 690-694.

Guinot B, Cachier H, Sciare J, Tong Y, Xin W and Jianhua Y 2007 Beijing aerosol: Atmospheric interactions and new trends; J. Geophys. Res. Atmos. (1984-2012) 112(D14).

Gupta A, Kumar R, Kumari K M and Srivastava S S 2003 Measurement of $\mathrm{NO}_{2}, \mathrm{HNO}_{3}, \mathrm{NH}_{3}$ and $\mathrm{SO}_{2}$ and related particulate matter at a rural site in Rampur, India; Atmos. Environ. 37(34) 4837-4846.
Hagler G S W, Bergin M H, Salmon L G, Yu J Z, Wan E C H and Zheng M 2006 Source areas and chemical composition of fine particulate matter in the Pearl River Delta region of China; Atmos. Environ. 40 3802-3815.

Hatch J P, Hearne E M and Clark G M 1982 A method of testing for serial correlation in univariate repeatedmeasures analyses of variance; Behav. Res. Methods 14(5) 497-498.

Hou Q, An X Q, Xing Q, Wang Z F, Wang Y and Sun Z B 2011 Assessment on health economic costs of particulate air pollution in Lanzhou during 2002-2009; J. Environ. Sci. (China) 31(8) 1398-1402.

Jones A M, Yin J and Harrison R M 2008 The weekdayweekend difference and the estimation of the non-vehicle contributions to the urban increment of airborne particulate matter; Atmos. Environ. 42(19) 4467-4479.

Li C, Du S Y, Bai Z P, Shao-fei K, Yan Y, Bin H and Li Z Y 2010 Application of land use regression for estimating concentrations of major outdoor air pollutants in Jinan, China; J. Zhejiang. Univ. Sci. A 11(11) 857-867.

Marr L C and Harley R A 2002 Spectral analysis of weekdayweekend differences in ambient ozone, nitrogen oxide, and non-methane hydrocarbon time series in California; Atmos. Environ. 36(14) 2327-2335.

MEP (Ministry of Environmental Protection of the People's Republic of China) 2013a National Standards on Environmental Protection: Technical Specifications for Installation and Acceptance of Ambient Air Quality Continuous Automated Monitoring System for $\mathrm{SO}_{2}, \mathrm{NO}_{2}, \mathrm{O}_{3}$ and $\mathrm{CO}$ (HJ 193-2013); Ministry of Environmental Protection, China, Beijing.

MEP (Ministry of Environmental Protection of the People's Republic of China) 2013b National Standards on Environmental Protection:Technical Specifications for Installation and Acceptance of Ambient Air Quality Continuous Automated Monitoring System for $\mathrm{PM}_{10}$ and $\mathrm{PM}_{2.5}$ (HJ 655-2013); Ministry of Environmental Protection, China, Beijing.

Qin Y, Tonnesen G S and Wang Z 2004 Weekend/weekday differences of ozone, $\mathrm{NO}_{\mathrm{x}}, \mathrm{CO}, \mathrm{VOCs}, \mathrm{PM}_{10}$ and the light scatter during ozone season in southern California; Atmos. Environ. 38(19) 3069-3087.

Quan J, Zhang X, Zhang Q, Guo J and Vogt R D 2008 Importance of sulfate emission to sulfur deposition at urban and rural sites in China; Atmos. Res. 89(3) 283288.

Sheppard L, Levy D and Checkoway H 2001 Correcting for the effects of location and atmospheric conditions on air pollution exposures in a case-crossover study; J. Expos. Anal. Environ. Epidemiol. 11 86-96.

Ta W, Wang T, Xiao H, Zhu X and Xiao Z 2004 Gaseous and particulate air pollution in the Lanzhou Valley, China; Sci. Total Environ. 320(2) 163-176.

Tao Y, Mi S and Zhou S 2014 Air pollution and hospital admissions for respiratory diseases in Lanzhou, China; Environ. Pollut. 185 196-201.

Wang S, Feng X, Zeng X, Ma Y and Shang K 2009 A study on variations of concentrations of particulate matter with different sizes in Lanzhou, China; Atmos. Environ. 43(17) 2823-2828.

Wang Y, Zhuang G, Tang A, Zhang W, Sun Y, Wang Z and An Z 2008 The evolution of chemical components of aerosols at five monitoring sites of China during dust storms; Atmos. Environ. 41(5) 1091-1106.

WHO (World Health Organization) 2005 World Health Organization Air Quality Guidelines Global Update; Report on a Working Group Meeting, Bonn, Germany, 18-20 October 2005, WHO Regional Office for Europe, E87950. 
Xie S, Yu T, Zhang Y, Zeng L, Qi L and Tang X 2005 Characteristics of $\mathrm{PM}_{10}, \mathrm{SO}_{2}, \mathrm{NO}_{\mathrm{x}}$ and $\mathrm{O}_{3}$ in ambient air during the dust storm period in Beijing; Sci. Total Environ. 345(1) 153-164.

Yang F, Tan J, Zhao Q, Du Z, He K, Ma Y and Chen G 2011 Characteristics of $\mathrm{PM}_{2.5}$ speciation in representative megacities and across China; Atmos. Chem. Phys. 11(11) 5207-5219.

Yao X, Chan C K, Fang M, Cadle S, Chan T, Mulawa P, He $\mathrm{K}$ and Ye B 2002 The water-soluble ionic composition of $\mathrm{PM}_{2.5}$ in Shanghai and Beijing, China; Atmos. Environ. 36 4223-4234.

Yu H and Yu J Z 2012 Polycyclic aromatic hydrocarbons in urban atmosphere of Guangzhou, China: Size distribution characteristics and size-resolved gas-particle partitioning; Atmos. Environ. 54 194-200.
Zhai G Y, Wang S G, Dong J Y and Shang K Z 2015 Lanzhou different diameter grain of atmospheric particulate matter pollution characteristics and the influence of meteorological factor analysis; Ecol. Environ. Sci. 24(1) $70-75$.

Zhang X Y, Arimoto R, Zhu G H, Chen T and Zhang G Y 1998 Concentration, size-distribution and deposition of mineral aerosol over Chinese desert regions; Tellus $B$ 50(4) 317-330.

Zhang X Y, Wang Y Q, Niu T, Zhang X C, Gong S L, Zhang Y M and Sun J Y 2012 Atmospheric aerosol compositions in China: Spatial/temporal variability, chemical signature, regional haze distribution and comparisons with global aerosols; Atmos. Chem. Phys. 12(2) $779-799$.

MS received 20 December 2015; revised 13 May 2016; accepted 16 May 2016

Corresponding editor: K KRISHNAMOORTHY 